\section{AYSÉN y el mercado}

Aysén crece casi al 20\% y su tasa de desempleo alcanza solo un 4,5\%, situándose por debajo de la tasa

natural que alcanza el 5\%. Entonces, ¿cuál es el fundamento del descontento de los compatriotas que habitan estas latitudes?

Por Gustavo Marcos E.*
Podemos ag
grandes áreas:

1. Necesidad de mejorar y aumentar bienes publicos en la región (salud, educación y hasta cierto punto conectividad. 2. Aplicar politicas que alteren las condiciones de equilibrio en el mercado de trabajo, bienes de primera necesidad combustibles.

3. Regulación de recursos naturales. 4. Cambios a la institucionalidad vigente de aprobación de megaproyectos y recaunómicas regionales.

En el primer pun to

Es las brechas de necesidades que se plantean, pero no es menos cierto que problemas de oferta en salud y educación los enfrentan los chilenos en todo el territorio nacional. En cuanto a las inversiones fisicas necesarias, se puede concordar un itinerario para satisfacer dichas necesidades. Frente a la interrogante de si e Estado podria estar creciendo desmedidamente en estas áreas, vale la pena recordar que no existen colegios particulares pagados ni clinicas privadas en la región plicos no expulsrian inversión privada. Cuando existen estas circunstancias la inversión pública en términos de crecimiento es muy positiva.

Pero existen problemas anexos que debe el Estado abordar: por ejemplo falta de médicos especialistas, un punto no bien resuelto que afecta la oferta de salud en regiones y que requiere una política de atracción de capital humano avanzado especial.

Tengo mis dudas acerca de si es pertinente instalar una universidad en una zona que solo posee 100.000 habitantes, y cuvas universidades estatales más cercanas no cubren la matricula en todas las carreinciativas que permitan subsidiar el miento de los estudiantes de esta región en ciudad donde decidan estudiar.

En cuanto a la infraestructura vial conectividad, las concesiones no parecen haber despertado interés en los privados en iniciar obras. Un plan de infraestructua que resuelva primero la conectividad de los grandes asentamientos urbanos parece lo corret sente que los subsidios no son otra cosa ativos y que van a alteforma estática sino también dinámica². Un ejemplo que no necesariamente representa casos reales de la región sirve para ilustrar posibles causas. Supongamos que se aprueba el subsidio de transporte a bienes et precio a consumidor sebera su el precio a consumidor debiera ser menor. bienes sustitutos podricon mercado. Entonces solo es plausiber dicha politica si las actividades productoras de bienes de primera necesidad no son muy importantes para el empleo. En cuanto a los servicios básicos, los subsidios deben ser focalizados y han de tener en cuenta el nivel de costo de la producción de dichos servicios.

El salario minimo es una política que busca proteger a las personas de menores ingresos. Aumentar el salario minimo en algunas regiones dado su alto costo de vida parece loable, pero depende también de las condiciones de mercado laboral lolas personas en general no migran entre regiones, entones el factor migaja entre bien fijo en Chile. En épocas de alto creafecta la cantidad de equilibrio de horas trabajadas, es decir, no resiente el empleo pero esto cambia cuando hay bajo crecimiento económico.

El aumento de la cuota pesquera artesanal busca proteger el empleo en la región. Pero la disminución de la cuota de pesca se debe a razones de sustentabilidad del recurso. Entonces se deben conjugar ambos objetivos: conservación del recurso y empleo en la región. Una medida que podría ayudar en este sentido serla dividir la pesca la propiamente artesana Las dismintiones de cuota con motivos de conservación debieran ser asumidas por el sector industrial y este nuevo sector semi industrial. Sin embargo el proyecto de ley de pesca recientemente enviado al congreso no incluye esta materia.

Respecto del último punto, aunque está fuera del ámbito de lo propiamente económico, la institucionalidad se ha revelado miento económico y el funcionamiento de los mercados. La aprobación de mega proyectos y la participación ciudadana son temas relevantes en muchos paises, en particular en el mundo emergente. De acuerdo a la experiencia mundial es poco consistente entregar todo el poder de decisión a una instancia local respecto de tienes que involucran a todo el pais. Pero sin duda que el proceso actual de decisión mita ciones de las comunidades lacies. La petición de regionalización de

cursos naturales no ha sido especifica suficientemente, pero debe involucrar agún tipo de recaudación aplicada a actividades económicas que se realicen en la región para financiar con libertad iniciativas públicas consideradas relevantes por las autoridades locales. En este sentido, debe recordarse que en Chile el Fondo Nacion de Desarrollo Regional (FNDR) entrega ecursos de eleccion de las autoridades egionales, pero quienes deciden sobre estos recursos (CORES e intendente) no so en ello puede explicar en parte los des

列 no es a tuz de la complementariedad do las acciones del mercado y los privados. considerando también los incentivos que producirán las diversas intervenciones de Estado no solo en la situación actual. Se requiere más que una negociación parcia con la región de Aysén. La politica del Estado con las regiones debe actualizarse considerando los nuevos minimos sociales de participación que parecen haber emer-

gido en nuestro pais. Ello requiere repens 